\title{
RANCANG BANGUN PROGRAM SISTEM TRANSAKSI PEMBAYARAN SPP (STPS) MENGGUNAKAN PHP STUDY KASUS MAN 2 MAJALENGKA
}

\author{
Deden Rizal Mantopani, Dadan Zaliluddin, \\ Teknik Informatika, Fakultas Teknik Universitas Majalengka \\ Email: deden.rizal@gmail.com, dadanzuu@gmail.com
}

\begin{abstract}
ABSTRACK
MAN 2 Majalengka stood on July 11, 1991. Design Build Transaction Payment System Program (STPS) Using PHP Case Study Man 2 Majalengka. Aiming to change the system of manual administration to be composision, Based on these requirements made Program System Support SPP Payment Transaction System Program using Object Oriented development techniques. While the method of data flow system using waterfall, where the tool is Unified Modeling Language (UML) to describe the functional model is use case diagram to describe the data model. The specialization process can be done with this application. After going through the stages in accordance with the selected development method then in implementing financial administration support system. After testing it can be concluded that the System is expected to assist in the administration record
\end{abstract}

Keywords : Decision Support System, waterfall, Object Oriented, PHP, Unified Modeling Language (UML)

\section{PENDAHULUAN}

Komputerisasi sangat penting dan besar manfaatnya dalam aktivitas dan pekerjaan manusia sehari-hari. Selain untuk keefektifan dan keefesienan waktu, juga data dan informasi yang dihasilkan lebih akurat dan berimbang. Banyak lembaga, instansi maupun perusahaan yang membutuhkan kemajuan teknologi untuk memperlancar proses aktivitas perusahaan. Salah satu instansi yang sangat membutuhkan jasa komputer sebagai alat pengolah data adalah sistem pembayaran SPP di MAN 2 Majalengka. Hal ini terjadi karena di tempat pembayaran SPP di MAN 2 Majalengka terdapat banyak kesulitan yang membutuhkan sebuah aplikasi program untuk mengatasi hal tersebut.

Oleh karena itu, pemakaian komputerisasi diharapkan bisa mengatasi apabila kita menginginkan suatu data yang terkendali dan terpercaya kita bisa memakai sistem pemrograman komputer yang salah satunya adalah Sistem Transaksi Pembayaran SPP (STPS) menggunakan php. Karena dalam pengolahan data lebih mudah, pencatatan dan pengambilan data lebih efektif dan penyajian informasi lebih akurat serta dapat mengurangi kesalahan manusia karena kekurangan dan keterbatasannya.

\section{METODE PENELITIAN}

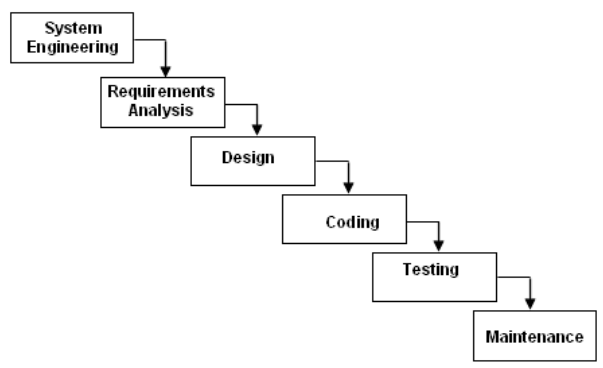

Gambar Metodologi Water Fall

Ganbar di atas adalah tahapan umum dari model proses ini. Akan tetapi Roger S. Pressman memecah model ini menjadi 6 tahapan meskipun secara garis besar sama dengan tahapan-tahapan model waterfall pada umumnya. Berikut adalah penjelasan dari tahap-tahap yang dilakukan di dalam model ini menurut Pressman:

1. System / Information Engineering and Modeling.

Permodelan ini diawali dengan mencari kebutuhan dari keseluruhan sistem yang akan diaplikasikan ke dalam bentuk software. Hal ini sangat penting, mengingat software harus dapat berinteraksi dengan elemen-elemen yang lain seperti hardware, database, dsb. Tahap ini sering disebut dengan Project Definition. 
2. Software Requirements Analysis.

Proses pencarian kebutuhan diintensifkan dan difokuskan pada software. Untuk mengetahui sifat dari program yang akan dibuat, maka para software engineer harus mengerti tentang domain informasi dari software, misalnya fungsi yang dibutuhkan, user interface, dsb.

3. Design

Proses ini digunakan untuk mengubah kebutuhan-kebutuhan diatas menjadi representasi ke dalam bentuk "blueprint" software sebelum coding dimulai. Desain harus dapat mengimplementasikan kebutuhan yang telah disebutkan pada tahap sebelumnya. Seperti 2 aktivitas sebelumnya, maka proses ini juga harus didokumentasikan sebagai konfigurasi dari software.

4. Coding

Desain yang telah dibuat kemudian diubah bentuknya menjadi bentuk yang dapat dimengerti oleh mesin, yaitu ke dalam bahasa pemrograman melalui proses coding. Tahap ini merupakan implementasi dari tahap design yang secara teknis nantinya dikerjakan oleh programmer.

5. Testing / Verification

Sesuatu yang dibuat haruslah diujicobakan. Demikian juga dengan software. Semua fungsifungsi software harus diujicobakan, agar software bebas dari error, dan hasilnya harus benar-benar sesuai dengan kebutuhan yang sudah didefinisikan sebelumnya.

\section{Maintenance}

Pemeliharaan suatu software diperlukan, termasuk di dalamnya adalah pengembangan, karena software yang dibuat tidak selamanya hanya seperti itu. Ketika dijalankan mungkin saja masih ada errors kecil yang tidak ditemukan sebelumnya, atau ada penambahan fitur-fitur yang belum ada pada software tersebut.

\section{HASIL DAN PEMBAHASAN}

Alur kegiatan transaksi pembayaran SPP di MAN 2 Majalengka yang pertama kali harus dilakukan adalah datang ke ruang tata usaha dan menyerahkan buku keuangan tanda pembayaran SPP, lalu pihak bagian keuangan menuliskan tanda pembayaran tersebut dibuku pembayaran SPP siswa, dan buku pembayaran milik TU.

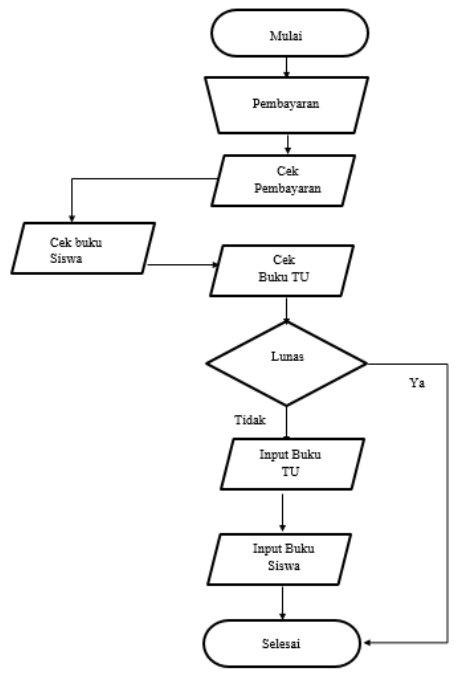

Seperti definisinya UML yaitu bahasa pemodelan untuk sistem atau perangkat lunak yang berorientasi objek dan digunakan untuk penyederhanaan permasalahan-permasalahan yang kompleks sedemikian rupa sehingga lebih mudah dipelajari dan dipahami. Untuk itu penulis membuat pemodelannya UMLnya yang meliputi Use Case Diagram, Class Diagram, Sequence Diagram, Activiy Diagram, Structure diagrams, Behavior diagrams, Interaction diagrams, Object Diagram, Component Diagram, Composite Struktur Diagram, Package Diagram, Deployment Diagram, Communication Diagram,Timing Diagram dan Interaction Overview Diagram.

\section{Usecase Diagram}

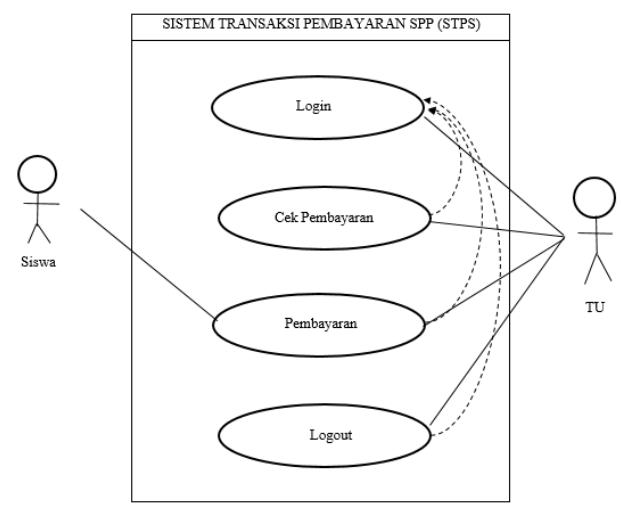




\section{Class Diagram}

Struktur dan deskripsi class serta hubungan antara class yang ada di Sistem Transaksi Pembayaran SPP (STPS) dapat di lihat seperti gambar berikut ini.

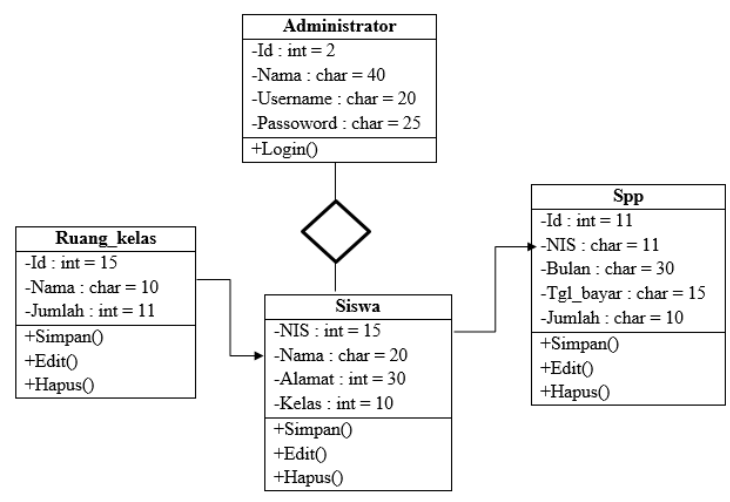

\section{Sequence Diagram}

Perancangan Sequence Diagram dibuat untuk menggambarkan kolaborasi dinamis antar sejumlah objek, kegunaannya untuk menunjukkan rangkaian pesan yang dikirim antar objek, dan juga interaksi antar objek.

Perancangan sequence diagram yang akan dibuat pada sub bab ini adalah diagram sequence Login, diagram sequence input siswa, diagram sequence input kelas, diagram sequence Input transaksi pembayaran spp, Perancangan Sequence Diagram Logins eperti yang terlihat pada gambar berikut ini.

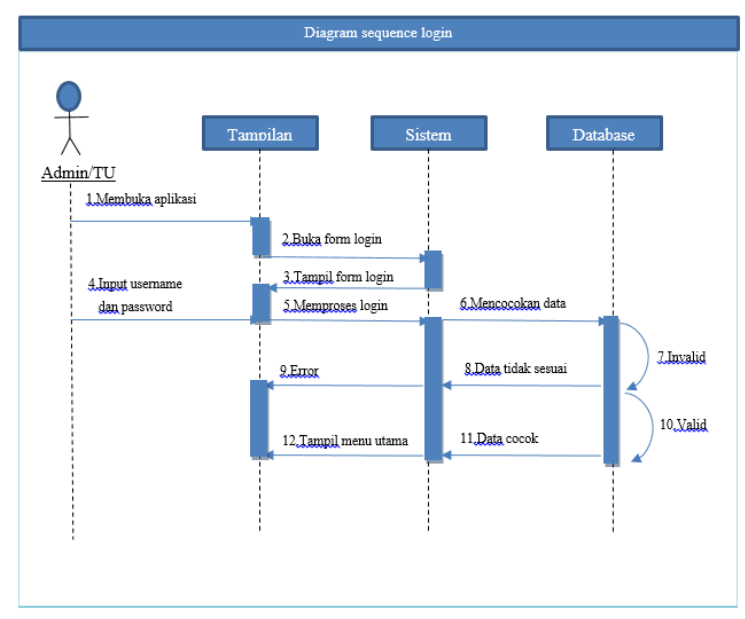

\section{Activity Diagram}

Diagram Activity yang menggambarkan aktifitas penggunaan Sistem Transaksi Pembayaran SPP, penulis buat berdasarkan form-form yang ada. Form yang terdapat di Sistem Transaksi Pembayaran SPP antara lain form login, form input siswa, input kelas dan input SPP. Diagram Activity Login Sistem Transaksi Pembayaran SPP seperti yang terlihat di gambar di bawah ini.

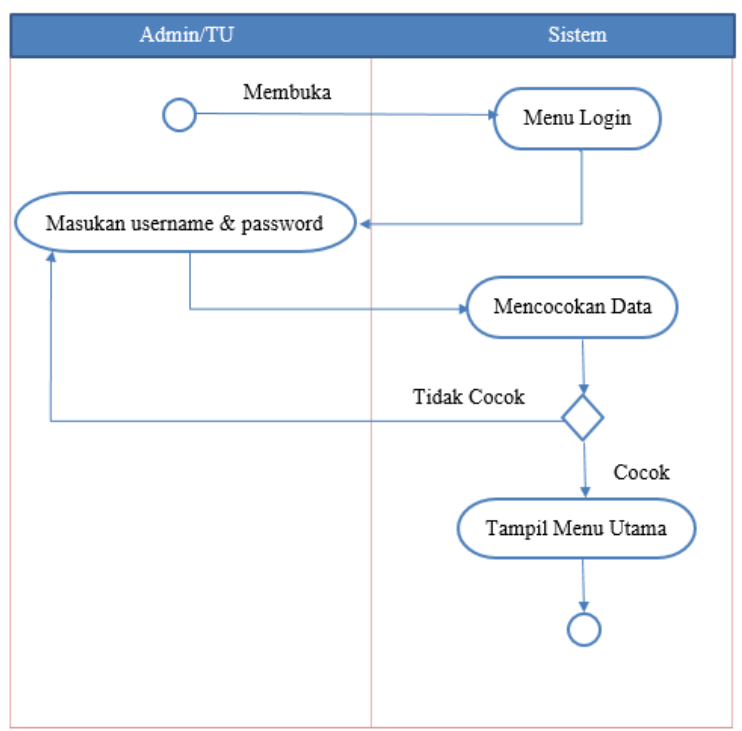

\section{Tampilan (User Interface)}

Setiap software aplikasi berbasis dekstop sudah pasti memiliki tampilan yang berfungsi untuk memudahkan pengguna dalam mengoprasikan aplikasi tersebut. Begitu pula aplikasi Sistem Pembayaran SPP (STPS) mempunyai tampilantampilan di setiap menunya. Perancangan tampilan Sistem Pembayaran SPP (STPS) menggunakan aplikasi dari Microsoft Office 2013 yaitu MS Office word 2013. Berikut gambar hasil perancangannya :

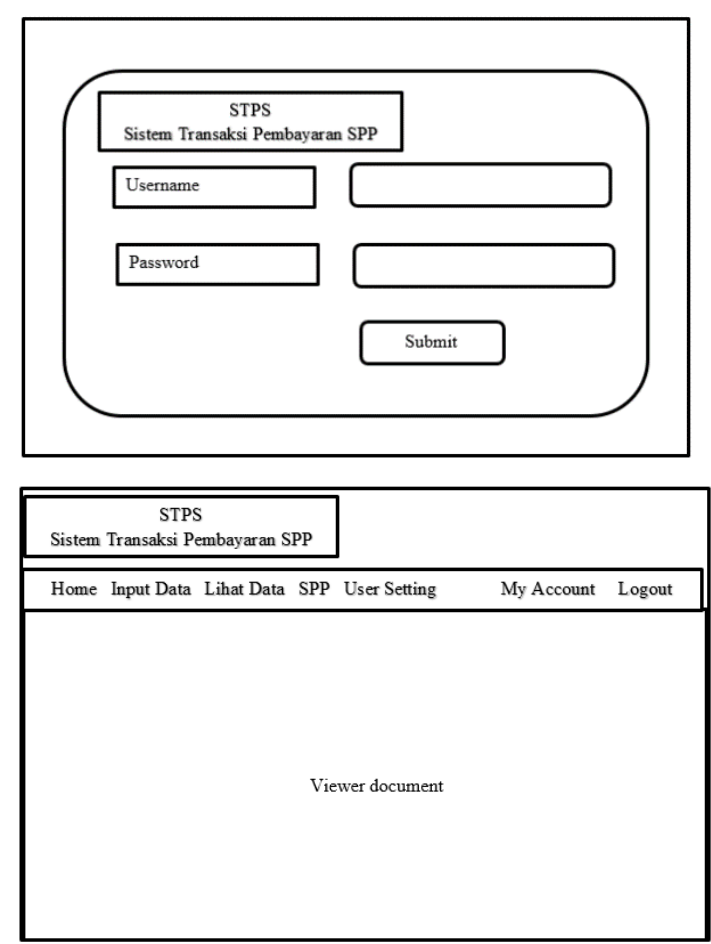


Berikut adalah implementasi dan testing interface dari program aplikasi Sistem Transaksi Pembayaran SPP(STPS).

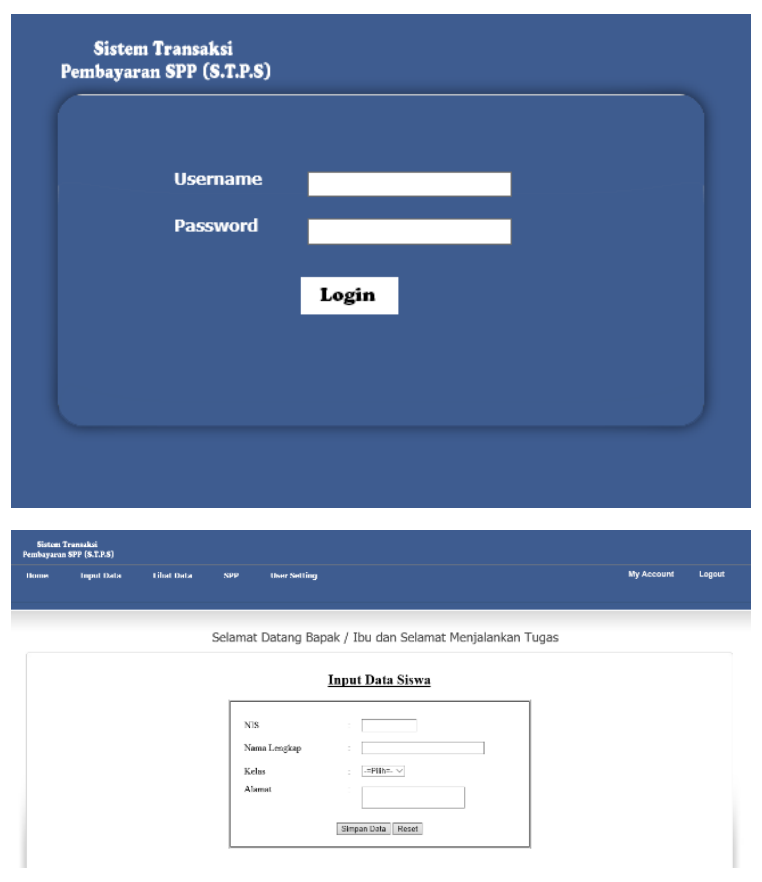

\section{KESIMPULAN}

Dengan memakai Sistem Transaksi Pembayaran SPP di MAN 2 Majalengka yang dibuat sesuai kebutuhan admin / TU bagian keuangan, dengan menggunakan aplikasi ini pekerjaan TU bisa dilakukan dengan cukup mudah yaitu melakukan pemilihan kelas mana yang ada siswa tersebut yang akan melakukan pembayaran, dan setelah itu admin hanya tinggal memilih siswa tanggal pembayaran, bulan pembayaran dan jumlah pembayaran.

Selain itu pencarian data siswa, kelas, maupun transaksi pembayaran menjadi lebih mudah karena admin cukup dengan membuka aplikasi dan memilih kolom kategori untuk mencari berdasarkan kategori, dan kolom satunya untuk mencari objeknya, masing-masing data akan ditampilkan, dan diharapkan aplikasi ini dapat digunakan sebagaimana mestinya dan bisa membantu proses transaksi pembayaran SPP menjadi lebih mudah dan cepat.

\section{REFERENSI}

Fathansyah. "Basis Data". Bandung: Informatika Bandung, 12 Desember 2014.

Jogiyanto, H. "Analisis dan Desain Sistem Informasi" (Edisi III ed.), andi, Yogyakarta, 2009.

Kotler, P. "Mahir menguasai dreamweaver", jilid-1 edisi Milenium. PT. Prehalindo, Jakarta, 2008.

Nugroho, A. "Rekayasa Perangkat Lunak Menggunakan UML". Yogyakarta: Andi Offset 21 Agustus 2014.

Moekijati. "Sistem Informasi. Prasojo, Jakarta, 2011.

M Salahudin Rosa A.S., "belajar SQL dalam 1 hari”, Informatika, 2013.

Mulyanto, A. "Sistem Informasi Konsep \& Aplikasi". Pustaka Pelajar, Yogyakarta, 2009.

Mustakini, J. H. "Sistem Informasi Teknologi", Andi Offset, Yogyakarta, 2009.

Rachman Hakim, "Jalan pintas menjadi master php", Gramedia, Jakarta, 2009.

Saladin, Djaslim, "Metode rekayasa perangkat lunak", Cetakan Ketiga, Linda Karya, Bandung, 2009. 